\title{
Education and Employment Outcomes from the RSA Data File for Transition-Age African American, White, and Hispanic Youth with Learning Disabilities
}

\author{
Eun Ji \\ James Schaller \\ Barbara Pazey \\ Kate Glynn
}

\begin{abstract}
Relationships among consumer demographic variables, services, and employment outcomes for 25,218 15 to 18 year old youth with learning disabilities were examined using the Rehabilitation Services Administration database from 2012. The 25,218 individuals were randomly split for cross-validation purposes into Sample One and Sample Two. A separate logistic regression was run for each sample. Variables significant for both samples included being African American, college and occupational training, and job placement. The correct classification of the logistic regression for Sample One was $67.1 \%$ and for Sample Two it was 66\%. African American males had significantly lower successful employment rates than White or Hispanic males. African American females had significantly lower successful employment rates than White or Hispanic females. Mean earnings per week for White males and females combined were significantly higher than African American males and females combined. Hypotheses for the above findings include White and Hispanic youth using job placement resources at educational institutions, cultural mistrust, and rehabilitation counselors following youth's expressed preferences. Implications for practice include engaging ethnically diverse consumers in vocational rehabilitation through an empowerment approach and viewing family involvement in transition planning as a continuum.
\end{abstract}

Keywords: transition, ethnically diverse youth, learning disabilities

$\mathrm{T}$ ransitioning from high-school to work and the community is an important time for youth with disabilities as they assume adult roles, and participation in post-secondary education and employment have long been acknowledged as desirable transition outcomes (Anderson \& Smart, 2010; Gerber \& Brown, 1997; Kochhar-Bryant, Bassett, Webb, 2009). However, ethnically diverse youth with disabilities have not achieved the same educational and employment outcomes as White youth with disabilities, as it has been reported that African American and Hispanic youth with disabilities have had lower rates of attending post-secondary education and lower employment rates than White youth with disabilities (Blackorby \& Wagner, 1996; Sanford et al., 2011).

A number of studies have reported graduation rates and post-secondary education participation rates for youth with disabilities, youth with LD, and youth from culturally linguistically diverse (CLD) backgrounds. For example, Blackorby and Wagner (1996) examined participation rates in postsecondary education from the 1980's to early 1990 and found rates increased over time with African American youth with disabilities at $12.7 \%$ in 1987 and $23.2 \%$ in 1990 , while White youth with disabilities were $14.8 \%$ in 1987 and $27.5 \%$ in 1990 , and Hispanic youth with disabilities were $9.9 \%$ and $27.7 \%$, respectively. In a more recent study, 
Newman, Wagner, Cameto, Knokey, and Shaver (2010) found that $35.5 \%$ of youth with LD had been enrolled in a two year or community college program, while $16.2 \%$ had enrolled in a four year college setting. Newman et al. (2010) also noted that for youth across all disability categories participation rates in post-secondary education settings varied by race/ethnicity with $33.1 \%$ of White youth having been enrolled in a two year or community college program, $16.2 \%$ enrolled in a four year college setting, and $20.7 \%$ had enrolled in a vocational business or technical school. For African American youth, 34.5\% had enrolled in a two year or community college program, while $5.3 \%$ had enrolled in a four year college setting, and $28 \%$ had been in a vocational business or technical school. For Hispanic youth, $27.2 \%$ had enrolled in a two year or community college program, $15.4 \%$ had enrolled in a four year college setting, and $25 \%$ had been in a vocational business or technical school.

The Alliance for Excellent Education (2012) reported a high school graduation rate for students with learning disabilities (LD) of $68 \%$ in 2011 , in comparison to $72 \%$ for students in the general population. Graduation rates for students in the general population were $78 \%$ for White students, $57 \%$ for African American students, and 58\% for Hispanic students (Alliance for Excellent Education, 2012). Recent research has indicated a drop out rate of $14.7 \%$ for youth with LD (Thurlow, 2012). However, dropout rates have been reported as high as $58.5 \%$ for youth with LD who received vocational rehabilitation (VR) services (Gonzalez, Rosenthal, \& Kim, 2011).

In examining employment outcomes from the 1980's to 1990, Blackorby and Wagner (1996) found that, although employment rates for African American youth with disabilities improved from $25.5 \%$ in 1987 to $47.3 \%$ in 1990, their rates still trailed employment rates for White youth with disabilities of $53.1 \%$ and $60.8 \%$, and rates for Hispanic youth with disabilities of $49.4 \%$ and $50.5 \%$, respectively.

More recently, employment rates from the National Longitudinal Transition Study - 2 (NLTS-2) for youth across all disability categories were $62.6 \%$ for White youth with disabilities, 35.2\% for African American youth with disabilities, and $53.8 \%$ for Hispanic youth with disabilities (Newman, Wagner, Cameto, \& Knokey, 2009). Newman et al. (2009) reported that the employment rate for White youth in comparison to Hispanic youth was not significant, but the rates for White and African American youth were. The employment rate for youth with LD across all racial/ethnic categories was $63.6 \%$. Newman et al (2009) also reported gender differences in employment rates for youth across all disability categories with $62.2 \%$ for males and $45.7 \%$ for females, although the difference in rates was not significant.

In making comparisons across time Newman et al. (2010) found that employment rates for youth with LD declined from $69.3 \%$ in 1990 to $62.5 \%$ in 2005 and average hourly wages fell from $\$ 9.70 / \mathrm{hr}$ in 1990 to $\$ 8.60 / \mathrm{hr}$ in 2005 . Average hourly wages in 2005 across youth in all disability categories were $\$ 9.50 / \mathrm{hr}$ for males and $\$ 7.40 / \mathrm{hr}$ for females, and youth worked an average of 35 hours per week.

The decline in employment rates over time for youth with LD is mirrored by national employment rates for teens without disabilities (teens aged $16-19$ years) as the employment rate for teens across all race/ethnicities fell from $57 \%$ in 1989 to $26.1 \%$ in 2011 (Sum \& Khatiwada, 2011). The national summer employment rates (when teen employment may be expected to be higher due to summer jobs) in 2011 were $38.4 \%$ for White, $18.6 \%$ for African American, and $21.3 \%$ for Hispanic teens (Sum \& Khatiwada, 2011).

There have been a number of studies on individuals with LD in the VR literature. A study specifically with African American youth with LD found a successful employment rate of $52 \%$, and $19 \%$ of youth participated in college training, while $19 \%$ received vocational training (Dunham et al., 1998). Gender differences have been found among transition-age youth with LD with females having higher high school graduation rates than males $(55 \%$ and $42 \%$, respectively) (Vogel \& Reder, 1998). Hayward and Schmidt-Davis (2003) noted that of the VR services received by youth with LD $16.3 \%$ participated in business/vocational training, $14.9 \%$ participated in two-year community college training, $12.7 \%$ participated in job placement, and $10.7 \%$ received job development services. Vocational rehabilitation services that have been found to promote successful employment with youth with LD have been job placement, job search, and college or university training (Bolton, Belini, \& Brookings, 2000).

Although there is variation in rates of participation in post-secondary education and employment for youth with disabilities across the preceding studies, in general African American youth with LD had lower rates of high school completion and participation in college, and lower rates of employment, in comparison to White and Hispanic youth with LD. In response to these findings for ethnically diverse youth with disabilities a number of issues have appeared in the literature including engaging culturally linguistically diverse (CLD) individuals in the VR process and system (Anderson \& Smart, 2010; Rosenthal \& Bervin, 1999; Taylor-Ritzler et al., 2010), transition planning with ethnically diverse parents and families (Alston, Gayles, Rucker, \& Hobson, 2007; Feist-Price \& Harris, 1994; Irving \& Hudley, 2005; Kim \& Morningstar, 2005; Landmark, Zhang, \& Montoya, 2007), constructive guidelines for collaboration in family and professional partnerships (Blue-Banning, Summers, Frankland, Nelson, \& Beegle, 2004; Kalyanpur \& Harry, 1997), and gender issues for youth with LD (Gil-Kashiwabara, Geenen, \& Powers, 2012; Hegewisch, Williams, \& Zhang, 2012; Linstrom, Benz, \& Doren, 2004). Although research on outcomes for transition age youth with LD have been reported in studies, research specific to culturally linguistically diverse youth with LD who received VR services that examined relationships between demographic characteristics, VR services, and education and employment outcomes has been limited. The purpose of this study was to examine educa- 
tion and employment outcomes, and relationships among demographic and VR case service variables for African American, White, and Hispanic youth with LD aged 15-18 years. The age range of 15 to 18 years at the time the individual applied for VR services was used to capture youth with LD earlier in their high school years as it has been noted that youth within this age range may be more likely to drop out of school (Gonzalez et al., 2011). Even though states may mandate school attendance until graduation or until the age of 16 years, and some states require students to stay in school until age 17 or 18 years, prior research has shown that youth with LD may drop out of school as early as 15 to 16 and $1 / 2$ years of age (Stearns \& Glennie, 2006; Thurlow, 2012).

The research questions were:

Research Question One: Are African American, White, and Hispanic males and females with LD aged 15 18 statistically significantly different on successful employment rates and mean earnings per week at employment?

Research Question Two: Are African American, White, and Hispanic males and females with LD aged 15 18 statistically significantly different on mean earnings per week at employment?

Research Question Three: Are individual demographic and case service variables statistically significantly related to successful employment for African American, White, and Hispanic youth with LD aged $15-18$ ?

\section{Methodology}

The design of this study was correlational (Shadish, Cook, \& Campbell, 2002). The Rehabilitation Services Administration (RSA) national 911 data file for 2012 was used. The RSA national data file is an annual data file on all individuals with disabilities who applied for services from the state/federal VR system.

\section{Participants}

There was a total of 25,218 youth with LD aged 15 - 18 . Of the 25,218 youth, $22.8 \%(n=5,764)$ were African American, 59.1\% $(n=14,907)$ were White, and $18 \%(n=$ 4,547) were Hispanic.

Of African American youth, males represented $61.2 \%(n=3,528)$ and females $38.8 \%(n=2,236)$. The mean age for males was 17.40 years, and for females 17.36 years. Eighty-seven percent of males $(n=3,092)$ and $88.5 \%$ of females $(n=1,981)$ were referred for VR services from elementary or secondary schools. Eighty-seven point six percent of males $(n=3,090)$ and $86.4 \%(n=1,932)$ of females received their primary source of income from family and friends. Next was public support (e.g., SSI, SSD) with males at $7.8 \%(n=275)$ and females $9.2 \%(n=207)$. Personal income was last for both males at $2.8 \%(n=100)$ and females $2.6 \%(n=58)$. Ninety-four percent of males $(n=$ $3,307)$ and $93.2 \%(n=2,084)$ of females were categorized as having a significant disability, indicating they had an impairment that seriously limited one or more functional ca- pacities and would potentially need multiple VR services over an extended period of time. The successful employment rate for males was $46 \%(n=1,620)$ and $42.4 \%(n=$ 949) for females.

Of White youth, males represented $61 \%(n=9,094)$ and females $38.9 \%(n=5,813)$. The mean age for males was 17.31 years, and for females 17.28 years. Eight-eight percent of males $(n=8,052)$ and $88 \%$ of females $(n=5,100)$ were referred for VR services from elementary or secondary schools. Ninety-three percent of males $(n=8,448)$ and $91.9 \%$ of females $(n=5,343)$ received their primary source of income from family and friends. Two point eight percent of males $(n=262)$ and $3.2 \%$ of females $(n=189)$ received public support (e.g., SSI, SSD) as their primary income. Personal income was last for both males at $2.8 \%(n=257)$ and females $1.4 \%(n=87)$. Ninety-six point two percent of males $(n=8,755)$ and $96.4 \%(n=5,607)$ of females were categorized as having a significant disability. The successful employment rate for males was $60.6 \%(n=5,511)$ and $53.6 \%(n=3,119)$ for females.

Of Hispanic youth, males represented $61.9 \%(n=$ $2,815)$ and females $38 \%(n=1,732)$. The mean age for males was 17.34 years, and for females 17.28 years. Eighty-seven percent of males $(n=2,441)$ and $89 \%$ of females $(n=1,544)$ were referred for VR services from elementary or secondary schools. Ninety point two percent of males $(n=2,539)$ and $90.4 \%(n=1,566)$ of females received their primary source of financial support from family/friends at application. Next was public support with males at $6.2 \%(n=175)$ and females $5.2 \%(n=91)$. Personal income was last for both males at $2.8 \%(n=80)$ and females $2.9 \%(n=51)$. Ninety-four point five percent of males $(n=2,662)$ and $95.7 \%(n=1,659)$ of females were categorized as having a significant disability. The successful employment rate for males was $60.6 \%(n=1,707)$ and $51 \%(n=885)$ for females. Levels of education at application and at closure, and primary source of support at application for participants are in Table 1.

\section{Variables and Data Analyses}

For research question one on differences between African American, White, and Hispanic males and females with LD on successful employment rates, successful employment rates were the number of youth employed for a minimum of 90 days divided by the total number of youth who received services for a given group. Successful employment rates were examined using Chi-square analyses to test for differences across African American, White, and Hispanic youth.

For research question two on differences between African American, White, and Hispanic males and females with LD on mean earnings per week at employment, mean earnings per week was the average pay for individuals within a given group at the time of employment. Analyses of variance (ANOVA) was used to test for differences between males and females within each group of youth and to test for differences across African American, White, and 
Table 1

Education and Primary Source of Support by Race and Gender for Youth with Learning Disabilities

\begin{tabular}{|c|c|c|c|c|c|c|c|c|c|c|c|c|}
\hline & \multicolumn{4}{|c|}{ White } & \multicolumn{4}{|c|}{ African American } & \multicolumn{4}{|c|}{ Hispanic } \\
\hline & \multicolumn{2}{|c|}{ Male } & \multicolumn{2}{|c|}{ Female } & \multicolumn{2}{|c|}{ Male } & \multicolumn{2}{|c|}{ Female } & \multicolumn{2}{|c|}{ Male } & \multicolumn{2}{|c|}{ Female } \\
\hline & $\mathbf{n}$ & $\%$ & $\mathbf{n}$ & $\%$ & $\mathbf{n}$ & $\%$ & $\mathbf{n}$ & $\%$ & $\mathbf{n}$ & $\%$ & $\mathbf{n}$ & $\%$ \\
\hline \multicolumn{13}{|l|}{$\begin{array}{l}\text { Level of Education at } \\
\text { Application }\end{array}$} \\
\hline Special Education & 1,178 & 12.95 & 762 & 13.11 & 704 & 19.95 & 449 & 20.08 & 705 & 25.04 & 396 & 22.86 \\
\hline Less than High School & 6,966 & 76.60 & 4,354 & 74.90 & 2,442 & 69.22 & 1,514 & 67.71 & 1,659 & 58.93 & 1,090 & 62.93 \\
\hline High School Graduate & 881 & 9.69 & 629 & 10.82 & 357 & 10.12 & 254 & 11.36 & 423 & 15.03 & 238 & 13.74 \\
\hline Associate Degree & 61 & 0.67 & 62 & 1.07 & 24 & 0.68 & 18 & 0.81 & 28 & 0.99 & 8 & 0.46 \\
\hline College or Graduate Degree & 8 & 0.09 & 6 & 0.10 & 1 & 0.03 & 1 & 0.04 & 0 & 0.00 & 0 & 0.00 \\
\hline \multicolumn{13}{|l|}{ Level of Education at Closure } \\
\hline Special Education & 1,064 & 11.70 & 628 & 10.80 & 887 & 25.14 & 508 & 22.72 & 520 & 18.47 & 284 & 16.40 \\
\hline Less than High School & 1,467 & 16.13 & 873 & 15.02 & 827 & 23.44 & 490 & 21.91 & 446 & 15.84 & 257 & 14.84 \\
\hline High School Graduate & 3,963 & 43.58 & 2,378 & 40.91 & 1,404 & 39.80 & 846 & 37.84 & 1,121 & 39.82 & 713 & 41.17 \\
\hline Associate Degree & 2,302 & 25.31 & 1,674 & 28.80 & 369 & 10.46 & 358 & 16.01 & 695 & 24.69 & 448 & 25.87 \\
\hline College or Graduate Degree & 298 & 3.28 & 260 & 4.47 & 41 & 1.16 & 34 & 1.52 & 33 & 1.17 & 30 & 1.73 \\
\hline \multicolumn{13}{|l|}{$\begin{array}{l}\text { Primary Source of Support at } \\
\text { Application }\end{array}$} \\
\hline Personal Income & 257 & 2.83 & 172 & 2.96 & 100 & 2.83 & 58 & 2.59 & 80 & 2.84 & 51 & 2.94 \\
\hline Family \& Friends & 8,448 & 92.90 & 5,343 & 91.91 & 3,090 & 87.59 & 1,932 & 86.40 & 2,539 & 90.20 & 1,566 & 90.42 \\
\hline Public Support (SSI, etc) & 262 & 2.88 & 189 & 3.25 & 275 & 7.79 & 207 & 9.26 & 175 & 6.22 & 91 & 5.25 \\
\hline All Other Sources & 106 & 1.17 & 87 & 1.50 & 55 & 1.56 & 32 & 1.43 & 20 & 0.71 & 24 & 1.39 \\
\hline N/A & 21 & 0.23 & 22 & 0.38 & 8 & 0.23 & 7 & 0.31 & 1 & 0.04 & 0 & 0.00 \\
\hline
\end{tabular}

Hispanic youth. The statistical program SPSS 19 (Norusis, 2010) was used for all analyses.

For research question three on individual demographic and case service variables that may be significantly related to successful employment for African American, White, and Hispanic youth with LD the criterion variable was successfully employed or not employed. Successful employment was defined as employment in a competitive, integrated setting for at least 90 days. The predictor variables included consumer demographic and VR service variables. Consumer demographic variables included race, gender, level of education at application, and primary source of support at application.

Vocational rehabilitation service variables included vocational rehabilitation counseling, college training, occupational training, job search assistance, job placement, and job readiness training. According to the RSA (2012) reporting manual, vocational rehabilitation counseling includes discrete therapeutic counseling and guidance services that are necessary for an individual to achieve an employment outcome that are distinct from general counseling and guidance provided to individuals dur-

Table 2

Services by Race and Gender for Youth with Learning Disabilities

\begin{tabular}{|c|c|c|c|c|c|c|c|c|c|c|c|c|}
\hline & \multicolumn{4}{|c|}{ White } & \multicolumn{4}{|c|}{ African American } & \multicolumn{4}{|c|}{ Hispanic } \\
\hline & \multicolumn{2}{|c|}{ Male } & \multicolumn{2}{|c|}{ Female } & \multicolumn{2}{|c|}{ Male } & \multicolumn{2}{|c|}{ Female } & \multicolumn{2}{|c|}{ Male } & \multicolumn{2}{|c|}{ Female } \\
\hline & $\mathrm{n}$ & $\%$ & $n$ & $\%$ & $\mathrm{n}$ & $\%$ & n & $\%$ & $\mathrm{n}$ & $\%$ & n & $\%$ \\
\hline Assessment & 5,282 & 58.08 & 3,384 & 58.21 & 2,088 & 59.18 & 1,326 & 59.30 & 1,818 & 64.58 & 1,137 & 65.65 \\
\hline $\begin{array}{l}\text { Vocational } \\
\text { Rehabilitation } \\
\text { Counseling \& Guidance }\end{array}$ & 5,688 & 62.55 & 3,528 & 60.69 & 2,455 & 69.59 & 1,574 & 70.39 & 1,807 & 64.19 & 1,167 & 67.38 \\
\hline College Training & 2,155 & 23.70 & 1,634 & 28.11 & 401 & 11.37 & 340 & 15.21 & 472 & 16.77 & 349 & 20.15 \\
\hline Occupational Training & 1,213 & 13.38 & 831 & 14.29 & 327 & 9.26 & 263 & 11.76 & 577 & 20.49 & 330 & 19.05 \\
\hline Job Readiness Training & 1,755 & 19.30 & 1,023 & 17.60 & 1,066 & 30.22 & 620 & 27.73 & 793 & 28.17 & 487 & 28.12 \\
\hline Job Search Assistance & 2,306 & 25.36 & 1,295 & 22.28 & 1,011 & 28.66 & 553 & 24.73 & 922 & 32.75 & 533 & 30.77 \\
\hline $\begin{array}{l}\text { Job Placement } \\
\text { Assistance }\end{array}$ & 3,181 & 34.98 & 1,804 & 31.03 & 1,599 & 45.32 & 916 & 40.97 & 984 & 34.96 & 585 & 33.78 \\
\hline
\end{tabular}


ing the rehabilitation process. College training is academic training leading to a degree, certificate, or other recognized educational credential. Occupational training is provided by a community college and/or business, vocational/trade, or technical school to prepare an individual for gainful employment that does not lead to an academic degree or certification. Job search assistance includes assistance with resume writing, making contacts with employers, developing interview skills, and identifying job opportunities. Job placement assistance is a referral to a specific job, resulting in an interview whether or not the person obtained a job. Job readiness training is training to prepare an individual to work including appropriate work behaviors, dress, and grooming. Services received by youth are in Table 2 . A total of ten demographic and VR service variables were entered (four demographic variables: race, gender, level of education at application, and primary source of support at application; and six VR service variables: VR counseling, college training, occupational training, job search assistance, job placement, and job readiness training) for each logistic regression equation.

Logistic regression was used as there was a combination of categorical and continuous variables with a categorical criterion variable (Field, 2009). For research question three, cross validation was used to randomly split participants into two samples, Sample One and Sample Two. This resulted in Sample One consisting of half the African American, White, and Hispanic youth and Sample Two the other half of African American, White, and Hispanic youth. This was done due to the concern that findings from logistic regression for a given sample may not generalize to a larger population (Cohen, Cohen, West, \& Aiken, 2003). Cross-validation with a second sample is recommended with variables that are significant for both samples being reported and interpreted (Cohen et al., 2003). The random sample feature of SPSS 19 was used to randomly split the samples (Norusis, 2010). There were no significant differences on demographic variables between Sample One and Sample Two.

A separate forward logistic regression was run for youth in Sample One and youth in Sample Two. Forward stepwise entry of the variables was chosen as it may be used as a hypothesis generating technique for statistically examining relationships among the variables.

Indicator coding was used for the logistic regression analyses in which the first category for a given variable is represented by a zero (Field, 2009). For example, having VR counseling was coded no as 0 and yes as 1 . Distributions of all predictor variables were examined prior to analyses. Cohen et al. (2003) has suggested that dichotomous variables with distributions of $80 \%$ to $20 \%$ are appropriate for logistic regression while dichotomous variables with distributions greater than this (e.g., $95 \%-5 \%$ ) should not be included. The VR service variable "on-the-job training" was not included in the analyses as the distribution was over the $95 \%-5 \%$ distribution. In addition, Pearson and Kendall's $t a u-b$ correlations were run on predictor variables. Inter-correlations among predictor variables ranged from
.27 to .35 and it was determined that these values were low enough to preclude issues of multi-collinearity.

\section{Results}

For research question one on differences between African American, White, and Hispanic males and females with LD on successful employment rates, successful employment rates for African American males was $46 \%$, for White males $60.6 \%$, and for Hispanic males $60.6 \%$. Successful employment rates for African American females was $42.4 \%$, in comparison to White females at $53.5 \%$, and Hispanic females at 51\%. African American males had significantly lower successful employment rates than White or Hispanic males, $\left(\chi^{2}(2)=17.14, p=.000\right)$. The successful employment rates of White and Hispanic males were not significantly different. African American females had significantly lower successful employment rates than White or Hispanic females, $\left(\chi^{2}(2)=16.7, p=.000\right)$. The successful employment rates of White and Hispanic females were not significantly different. The mean rate of successful employment for African American, White, and Hispanic males of $55.7 \%$ was not significant from the mean rate of $49 \%$ for African American, White, and Hispanic females.

In regard to research question two on differences between African American, White, and Hispanic males and females with LD on mean earnings per week, White males mean earnings were \$353.6, White females \$288.7, Hispanic males \$312.7, Hispanic females \$279.2, African American males \$276.2, and African American females \$260.1. White males had significantly higher mean earnings than White females $F(1,13,833)=127.35, p=.000$, and Hispanic males also had significantly higher mean earnings than Hispanic females $F(1,4,545)=131.35, p=$ .000. African American male and female mean earnings per week were not significantly different from each other. Post hoc Scheffe tests found mean earnings per week for White males and females combined (\$321.1) were significantly higher than African American males and females combined $(\$ 268.1)$ (mean difference $=59.93, p=.000)$, but not significantly higher than Hispanic males and females combined (\$295.9).

For research question three on demographic and case service variables significantly related to successful employment for African American, White, and Hispanic males and females with LD, Cohen et al. (2003) recommends reporting the variables that were significant for both samples. For Sample One, of the ten variables entered for the logistic regression for youth the status of African American was negatively related to successful employment $(\beta=$ $.570, S E=.034$, Wald $=273.45, p=.000, \operatorname{Exp}(\beta)=.566)$; job placement was positively related to successful employment $(\beta=1.058, S E=.033$, Wald $=311.41, p=.000$, $\operatorname{Exp}(\beta)=2.88)$, college training was positively related to successful employment $(\beta=.577, S E=.035$, Wald $=$ $277.77, p=.000, \operatorname{Exp}(\beta)=1.78)$, and occupational training was positively related to successful employment $(\beta=.828$, 
$S E=.042, \mathrm{Wald}=383.49, p=.000, \operatorname{Exp}(\beta)=2.28)$. Correct classification was $67.1 \%$. The Cox and Snell $R^{2}$ was .143 and the Negelkerke $R^{2}$ was .191.

For youth in Sample Two, the status of African American was negatively related $(\beta=-.510, S E=.037$, Wald $=223.40, p=.000, \operatorname{Exp}(\beta)=.585)$; job placement was positively related $(\beta=1.09, S E=.037$, Wald $=301.41, p=$ $.000, \operatorname{Exp}(\beta)=2.23)$; college training was positively $(\beta=$ $.503, S E=.040$, Wald $=299.03, p=.000, \operatorname{Exp}(\beta)=1.88)$, and occupational training was positively related to successful employment $(\beta=.806, S E=.045$, Wald $=390.04, p=$ $.000, \operatorname{Exp}(\beta)=2.19)$. Correct classification was $66 \%$. The Cox and Snell $R^{2}$ was .124 and the Negelkerke $R^{2}$ was .178.

\section{Discussion}

For research question one on employment rates, African American males had significantly lower successful employment rates than White and Hispanic males, and African American females had significantly lower successful employment rates than White and Hispanic females. Higher employment rates for White youth with disabilities and Hispanic youth with disabilities in comparison to African American youth with disabilities have been reported by Blackorby and Wagner (1996) and Newman et al. (2009). However, employment rates for White and Hispanic males and females in this study were virtually the same.

Disparities in successful employment rates along race/ethnicity lines may be attributed to a variety of factors (Alston et al., 2007; Taylor-Ritzler et al., 2010). The similar employment rates for White and Hispanic youth could be an artifact of the sample used for this study. However, for level of education at closure there were higher participation rates in associate degree and college/graduate degree programs by White and Hispanic youth in this study in comparison to African American youth, and it may be possible that White and Hispanic youth used the employment placement resources of these educational institutions to assist with finding employment.

Another possible hypothesis for African American youth having lower employment rates than their counterparts may be that African American youth and/or their family did not agree with the types of employment suggested by VR counselors. Alston et al. (2007) noted that some African American clients of VR who received employment services disliked being placed in jobs they felt did not fit their skill sets or that failed to take into account race relations in a particular employment situation, which may contribute to mistrust of the counselor, the VR process, VR system, and unsuccessful employment outcomes. African American consumers of VR services have also noted feeling that their VR counselor lacked awareness of issues of race and disability, and that this impacted communication in the counseling relationship and employment outcomes.

In addition, national summer employment rates for teens without disabilities in 2011 were lowest for African American teens in comparison to White and Hispanic teens (Sum \& Khatiwada, 2011). As such, lower successful em- ployment rates for African American teens with LD in this study may reflect a structural issue of higher unemployment rates for African Americans in general in comparison to unemployment rates of Whites and Hispanics in general. Although national unemployment rates have fallen for White and Hispanic workers without disabilities since 2009, national unemployment rates for African American workers without disabilities remain higher than White or Hispanic workers without disabilities (UC Berkeley Labor Center, 2012)

For research question two in regard to mean earnings per week, there were gender differences with White males and Hispanic males having higher mean earnings than White females and Hispanic females, respectively. There was a difference by race/ethnicity with mean earnings for White males and females combined having significantly higher mean earnings than African American males and females combined. In comparison, Newman et al. (2009) and Newman et al. (2010) reported no differences by gender or race in mean wages.

The average weekly wage for White females (\$288.67) in this study was $81.6 \%$ of the average weekly wage for White males (\$353.57) and the average weekly wage for Hispanic females (\$259.55) was $87.5 \%$ of the average weekly wage for Hispanic males (\$296.58). Unfortunately, the gender difference found in this study for White and Hispanic youth is similar to wages for men and women in the general population as males typically earn more than females. In comparison, the full-time median weekly wage for White women without disabilities was $\$ 698.00$ in 2011, which was $82 \%$ of the full-time weekly wage for White men without disabilities of $\$ 849.00$ (Hegewisch et al., 2012). However, closing the gender wage gap is important as women's wages have become more important for family incomes and the continuing gender wage gap hurts not only women but their families as well (Hegewisch et al., 2012).

The difference by race/ethnicity in this study is also reflected in the general population as White workers typically earn more than African American workers (Hegewisch et al., 2012). The lack of a significant difference between African American males and females in this study is also reflected in the general population as the gender pay gap is typically smallest between African American male and female workers (Sum \& Khatiwada, 2011).

For participants in this study, level of education may account for some of the differences in mean earnings. At application for VR services there were high levels of having less than a high school education for all youth in this study. The rates of having less than a high school education for participants in this study were higher than has been reported previously for youth with LD (Gonzalez et al., 2011; Thurlow, 2012). White youth had the highest rates of less than a high school education, with African American youth having rates between White and Hispanic youth. However, the education levels of youth at the time their file was closed indicate that levels of education increased for all youth but with variations. The largest variation was with youth with an associate degree or higher, with White males and fe- 
males and Hispanic males and females having higher rates of an associate degree than African American males and females. Percentages of White males and females having a college/graduate degree were also slightly higher than African American or Hispanic males and females.

In a study on White preservice counselor's perspectives of a White or African American individual, Rosenthal and Bervin (1999) reported that White preservice counselors viewed an African American consumer less favorably for additional education services and employment than an identical White consumer, based on case materials provided. If VR counselors viewed African American youth in this study as less able academically for an associate or college degree, and Hispanic youth for a college degree, than their White counterparts it could have impeded the counseling process. If this occurred it may potentially have made it difficult for African American or Hispanic youth to identify their goals and desires.

Feist-Price and Harris (1994) noted that African American individuals may have difficulty identifying their goals if a VR counselor reminds them of negative past experiences. Negative past experiences could include perceptions of not being listened to by teachers or counselors or of being valued less than someone with a different skin color. Perceptions of negative past experiences, if held by African American individuals, may contribute to cultural mistrust of counselors. The issue of cultural mistrust can be related to perceptions of outcome expectations and outcome values (Irving \& Hudley, 2005). Ethnically diverse individuals, if perceiving racism, may not expect to control access to, in this case education, regardless of the effort an individual puts forth. This may lead to devaluing academic accomplishments and striving as an individual does not expect their effort to yield benefits. And, if high levels of effort does not lead to success, this may convey a message of personal incompetence that may lead to diminished self-worth. Rather than run the risk of confirming a stereotype of ethnically diverse individuals as academically inferior, ethnically diverse youth may dis-identify with academic activities/goals (Irvin \& Hudley, 2005).

Another speculative hypothesis is that rehabilitation counselors may have been following youth's expressed preferences. Based on rates of provision of vocational rehabilitation counseling in Table 2, counselors appeared to engage with African American and Hispanic males and females in therapeutic counseling and guidance. What is not known is if African American males and females were telling counselors they did not want post secondary education services, and Hispanic males and females were telling counselors that they did not want college services, especially if it meant years of school, and instead wanted to obtain employment quickly. Landmark et al. (2007) noted that African American and Hispanic parents may prioritize employment over postsecondary education for their children as a means of contributing financially to the family.

In regard to research question three, being African American was negatively significantly related to successful employment. As mentioned, a number of studies have found lower employment rates for African American youth with LD in comparison to White youth with LD and Hispanic youth with LD including Gonzalez et al. (2011), Blackorby and Wagner (1996), and Newman et al. (2009). Issues that may have contributed to this finding include those discussed above on the possible lack of agreement on types of employment, higher participation rates by White and Hispanic youth in comparison to African American youth in post-secondary education, cultural mistrust, and the expressed preferences by African American youth in this study.

Job placement was also found to be related to successful employment with youth with LD in this study. Hayward and Schmidt-Davis (2003) and Bolton et al. (2000) also found job placement to be related to successful employment outcomes for individuals with LD. For the individuals in this study who received job placement there was an over all successful employment rate of $68.2 \%$. Job placement services have been found to be related to successful employment in a number of studies including individuals with spinal cord injuries (Marini, Lee, Chan, Chapin, \& Romero, 2008), psychiatric disabilities (Bolton et al., 2000), and depressive/mood disorders (Schaller \& Yang, 2007).

College and occupational training were also related to successful employment. For those individuals who received college training there was an overall successful employment rate of $60 \%$. For those individuals who received occupational training the overall successful employment rate was $68.23 \%$. Bolton et al. (2000) also found college training to be related to successful employment outcomes for individuals with $\mathrm{LD}$, and college training has also been reported as positively related to successful employment for individuals with spinal cord injuries (Marini et al., 2008), psychiatric disabilities (Bolton et al., 2000), and depressive/mood disorders (Schaller \& Yang, 2007). As mentioned previously, youth in this study who received college or occupational training may also have used the employment placement resources of the educational institutions they attended to assist with finding employment.

\section{Limitations}

There are a number of limitations to this study in regard to internal, external, and construct validity. Non-probability sampling was used limiting inferences to other populations. Use of logistic regression in this study was for model building through a correlational design, and the research design prohibits casual inferences. The categories of African American, White, and Hispanic in the RSA data file does not capture the variability of individuals who reside in the U.S. In addition, learning disability as defined in the RSA national data file does not capture the variability in individual functioning. The definition of variables in the RSA national data file such as diagnosis and treatment and college training may be defined and implemented in a number of ways. Even with a cross-validation sample, the statistical analysis may be population specific as it is possible for the 
logistic regression to classify the original data well, but may not replicate the findings if a new data set is used.

\section{Implications for Practice and Future Research}

Four implications for practice include: counselor's use of an empowerment philosophy in counseling (Taylor-Ritzler et al. (2010); characteristics identified by ethnically diverse parents of professionals who made a positive difference in the life of their child (Kim \& Morningstar, 2005; Landmark et al., 2007); guidelines for collaboration identified by ethnically diverse parents (Blue-Banning et al., 2004); and gender issues in wages (Hegewisch et al., 2012).

Use of an empowerment philosophy in counseling. Taylor-Ritzler et al. (2010) noted that the most significant contributor to successfully engaging ethnically diverse consumers in the VR system was an empowerment philosophy in counseling (Taylor-Ritzler et al., 2010). This philosophy included four dimensions and the belief that all persons are entitled to become the best they can be.

The first dimension of an empowerment philosophy was assisting consumers to understand their responsibilities in the rehabilitation process and in employment. For example, counselors assisted consumers to identify with an employer's perspective if an employee was consistently late or not performing well on the job. By consumers putting themselves in an employer's position they were able to recognize their responsibilities as an employee. Counselors also assisted consumers to personally engage with developing a vision and plan for their future success through the VR process.

The next dimension was consumers learning to advocate for themselves and work successfully with the VR system (Taylor-Ritzler et al., 2010). Counselors assisted consumers to feel a sense of power and control over their lives and the VR process by encouraging them to identify a career goal or goals, identify the steps needed to reach a goal, and then act on steps to accomplish that goal. Counselors worked with consumers to identify how they would map out taking control at each step of the process.

A third dimension was building a therapeutic relationship through identifying and supporting the goals and wishes of the consumer. This included discussion of and honoring consumer's feelings, to the extent that a consumer was comfortable discussing them, about participating in different education and/or training programs related to how a consumer would identify and meet their career goal(s).

A fourth dimension was working with consumers to maintain motivation to address barriers that could include limited employment or educational opportunities, transportation options, or coping with their disability. Taylor-Ritzler et al. (2010) also noted that some consumers may struggle to develop and/or implement an Individualized Plan of Employment immediately after eligibility determination, and consumers may need support to develop an understanding and appreciation of their capacity for success in education and employment. Working with ethnically di- verse consumers with disabilities to develop control over the processes that directly affected their lives was considered a critical component of an empowerment philosophy by counselors.

Characteristics of professionals identified by ethnically diverse parents. Characteristics identified by ethnically diverse parents that made a positive difference in their lives and the life of their child included professionals who were honest, clear, and knowledgeable (Kim \& Morningstar, 2005; Landmark et al., 2007). Professionals who made parents and family members feel as if they were welcome and their perspective had value were important. Parents indicated a need for information, and professionals who addressed strengths of their son or daughter and readily shared information about the range of services pertaining to transition, education, and employment were considered positively by parents (Kim \& Morningstar, 2005). In addition, counselors took into consideration a family's decision making process and viewed family involvement in the transition process as a continuum from uninvolved to very involved to represent not only the range of differences between families, but also the changing dynamics of an individual family as part of the process. Families that appear uncooperative or uninvolved may be so due to a fear of losing financial benefits, or concern for their son or daughter being in the community. Passive participation should not be labeled as uncaring, and professionals may need to consider that limited family participation may not reflect "informed choice." If a family chooses minimal participation, professionals should ensure that the choice is not due to lack of information, but is a free and informed choice (Landmark et al., 2007).

Although parents may use informal supports in their community, professionals can assist families in identifying formal and informal supports, not only for their child but also for parents and the family. Community organizations, community centers, and religious institutions can be identified to help professionals and families identify and coordinate, in combination with formal supports, available support networks. This may promote family involvement, as families may feel best supported and understood when combinations of formal and informal supports are used (Landmark et al., 2007).

Guidelines for collaboration identified by ethnically diverse parents. Ethnically diverse parents have also identified guidelines for collaboration that includes the quality of communication (Blue-Banning et al., 2004). Parents commented on professionals being open, with provision of information about resources that was free of jargon. Professionals mentioned the need for checking tactfully to make sure parents and youth understood the information that was provided, both verbally and in reports or other documents. Parents emphasized that they wanted to feel as if professionals were committed to their work, and by extension to the family. Examples were the willingness of professionals to meet in the community or home of the family (Blue-Banning et al., 2004). 
Trust was identified by parents as critical in relationships with professionals and it had three meanings. First was reliability or the sense that people were trustworthy and could be depended upon to follow through with what they were going to do. Trust also meant safety, in that parents could trust their child would be safe in the community and treated with dignity. Trust also meant discretion, in that professionals could be trusted with information about the family and that their confidence would not be violated.

Respect was intermingled with trust. For parents, professionals showing respect meant valuing the child as a person. Respect could also mean courtesy for calling parents by their last names until given permission to use a given name, acknowledging parent's contributions and efforts, and being nonjudgmental toward a family's lifestyle, values, and expectations. Respect also intermingled with equality, or a working relationship that had a sense of harmony or ease. Parents noted professionals who did not treat people as beneath them, and who actively empowered family members, as opposed to discounting or ignoring them. Professionals who actively encouraged family members to express opinions, within family guidelines, and who helped family members to participate fully in the process were valued (Blue-Banning et al., 2004).

Gender issues in wages. A fourth implication is gender issues in wages. It may be argued that wages of participants in this study reflected gender differences in society as a whole, but closing the wage gap may be important for a variety of reasons including the importance of women's earnings to family incomes and self-sufficiency for women (Hegewisch et al., 2012). Young women may retain responsibility for home and children regardless of working outside the home and may make work choices that allow greater flexibility in working to accommodate those responsibilities. Rehabilitation professionals can assist transition age women with LD to identify personal strengths and interests in order to consider educational and occupational choices in traditional and nontraditional occupations that may also lead to higher earnings (Gil-Kashiwabara et al., 2012). Structured opportunities including job shadows or site visits may give young women more options for consideration, even if they choose greater flexibility in employment over higher wages (Linstrom et al., 2004).

Suggestions for future research include a need for additional studies on VR outcomes with CLD youth with LD. It would be of interest to know if the participant's high rates of having a less than high school education at application for services and similar employment rates for White and Hispanic males and females at closure were specific to the population for this study or would generalize to other youth. It would also be of interest to use qualitative research to examine the decision process for youth and families on issues of education and employment to learn what factors may impact pursing additional education instead of employment. Finally, with an increased focus by state-federal VR agencies on competitive employment for people with disabilities in general, research to examine trends for individuals with LD may be useful for comparison of findings, and for documenting progress in service provision with individuals with LD.

\section{Conclusion}

The results of this study indicated that African American males and females had significantly lower rates of successful employment than White or Hispanic males and females. African American males and females also had significantly lower mean earnings per week than White or Hispanic males and females. White and Hispanic males had significantly higher mean wages than White or Hispanic females. Being African American was negatively related to successful employment. Job placement, college training, and occupational training were positively related to successful employment. Implications for increasing successful employment rates and mean earnings per week for African American consumers may include counselor's use of an empowerment philosophy of counseling, characteristics identified by ethnically diverse parents of professionals who made a positive difference in the life of their child, and guidelines for collaboration identified by ethnically diverse parents.

\section{References}

Alliance for Excellent Education (2012). Caught in the crisis: Students of color and Native students in U.S. high schools. Retrieved March 30, 2014 from: www.all4ed.org/files/CaughtCrisisSOC .pdf

Alston, R., Gayles, T., Rucker, R., \& Hobson, M. (2007). The centrality of race in rehabilitation: Views of former clients who are African American. Journal of Applied Rehabilitation Counseling, $38(1), 12-19$.

Anderson, C., \& Smart, J. (2010). Improving transition outcomes for culturally and linguistically diverse VR consumers. Journal of Applied Rehabilitation Counseling, 31(4), $3-10$.

Blackorby, J., \& Wagner, M. (1996). Longitudinal post-school outcomes of youth with disabilities: Findings from the National Longitudinal Transition Study. Exceptional Children, 67(5), 399 413.

Blue-Banning, M., Summers, J., Frankland, H., Nelson, L., \& Beegle, G. (2004). Dimensions of family and professional partnerships: Constructive guidelines for collaboration. Exceptional Children, 70(2), $167-184$.

Bolton, B., Belini, J., \& Brookings, J. (2000). Predicting client employment outcomes from personal history, functional limitations, and rehabilitation services. Rehabilitation Counselor Bulletin, 44(1), $10-21$.

Cohen, J., Cohen, P., West, S., \& Aiken, L. (2003). Applied multiple regression/correlation analysis for the behavioral sciences. (3rd ed.). Mahwah, New Jersey: Lawrence Erlbaum.

Dunham, M., Holliday, G., Douget, R., Koller, J., Presberry, R., \& Wooderson, S. (1998). Vocational rehabilitation outcomes of African American adults with specific learning disabilities. Journal of Rehabilitation, $36-41$.

Feist-Price, S., \& Harris, D. (1994). Rehabilitation counseling: Issues specific to providing services to African American clients. Journal of Rehabilitation, 13 - 19

Field, A. (2009). Discovering statistics using SPSS. (3rd. ed.). London: Sage.

Gerber, P., \& Brown, D. (1997). (Eds.). Learning disabilities and employment. Austin, TX: Pro-Ed.

Gil-Kashiwabara, E., Geenen, S., \& Powers, L. (2012). Expecatations and experiences of Latina and Anglo girls and parents for live 
after high school. Multiple Voices for Ethnically Diverse Exceptional Learners, 13(1), 5- 25.

Gonzalez, R., Rosenthal, D., \& Kim, J. (2011). Predicting vocational rehabilitation outcomes of young adults with specific learning disabilities: Transitioning from school to work. Journal of Vocational Rehabilitation, 34, $163-172$.

Hegewisch, A., Williams, C., \& Zhang, A, (2012). The gender wage gap: 2011. Washington, D.C.: Institute for Women's Policy Research, Retrieved March 14, 2014 from http://www.iwpr.org.

Irving, M., \& Hudley, C. (2005). Cultural mistrust, academic outcome expectations, and outcome values among African American adolescent men. Urban Education, 40(5), 476 - 496.

Kalyanpur, M., \& Harry, B. (1997). A posture of reciprocity: A practical approach to collaboration between professionals and parents of culturally diverse backgrounds. Journal of Child and Family Studies, 6(4), $487-509$.

Kim, K., \& Morningstar, M. (2005). Transition planning involving culturally and linguistically diverse families. Career Development for Exceptional Individuals, 28(2), 92 - 103.

Kochhar-Bryant, C., Bassett, D., Webb, 20 K. (2009). Transition to postsecondary education for students with disabilities. Thousand Oaks, CA: Corwin Press.

Landmark, L., Zhang, D., \& Montoya, L. (2007). Culturally diverse parents' experiences in their children's transition: Knowledge and involvement. Career Development for Exceptional Individuals, 30(2), $68-79$.

Linstrom, L., Benz, M., \& Doren, B. (2004). Expanding career options for young women with learning disabilities. Career Development for Exceptional Individuals, 27(1), 43 - 63.

Marini, I., Lee, G., Chan, F., Chapin, H., \& Romero, M. (2008). Vocational rehabilitation service patterns related to successful employment of persons with spinal cord injury. Journal of Vocational Rehabilitation, 28, 1-13.

Newman, L., Wagner, M., Cameto, R., Knokey, A. (2009). The post-high school outcomes of youth with disabilities up to 4 years after high-school. A report from the National Longitudinal Transition Study-2 (NLTS2) NCSER (2009-3017) Menlo Park, CA: SRI International.

Newman, L., Wagner, M., Cameto, R., Knokey, A., \& Shaver, D. (2010). Comparisons across time of the outcomes of youth with disabilities up to 4 years after high school: A report of findings from the National Longitudinal Transition Study-2 (NLTS-2). (NCSER-2011-3005). Menlo Park, CA: SRI International.

Norusis, M. (2010). IBM SPSS Statistical 19 Statistical Procedures Companion. Upper Saddle River, NJ: Prentice Hall.

Rehabilitation Services Administration. (2012). Reporting manual for the case service report. (RSA 911). (RSA-PD-09-01). Washington, D.C.: Author.

Rosenthal, D., \& Bervin, N. (1999). Effect of client race on clinical judgment. Rehabilitation Counselor Bulletin, 42(3), 243 - 264.
Sanford, C., Newman, L., Wagner, M., Cameto, R., Knokey, A., \& Shaver, D. (2011). The Post High School Outcomes of Youth with Disabilities up to 6 years after High School: Key findings from the National Longitudinal Transition Study-2 (NLTS2) (NCSER 2011-3004). Menlo Park, CA: SRI International.

Schaller, J., \& Yang, N. (2007). Gender, race, and depressive/mood disorders: An analyses of State/Federal rehabilitation outcomes. Journal of Applied Rehabilitation Counseling, 38(1), 32 - 38.

Shadish, W., Cook, T., \& Campbell, D. (2002). Experimental and quasi-experimental designs for generalized causal inference. Boston, MA: Houghton Mifflin.

Stearns, S., \& Glennie, E. (2006). When and why dropouts leave high school. Youth Society, 38, $29-57$.

Sum, A., \& Khatiwada, I. (2011). The continued collapse of the nation's teen summer job market: Who worked in the summer of 2011? Center for Labor Market Studies Publications. Paper 34.

Taylor-Ritzler, T., Balcazar, S., Suarez-Balcazar, Y., Lilbury, R., Alvarado, F., \& James, M. (2010). Engaging ethnically diverse individuals with disabilities in the vocational rehabilitation system: Themes of empowerment and oppression. Journal of Vocational Rehabilitation, 33, 3-14.

Thurlow, M. (2012). Addressing the dilemma of high school dropouts with LD. Retrieved September 31, 2013 from http://www.ncld. org/ld-insights/entr/1/326

UC Berkeley Labor Center. (2012). Annual Report: Black employment and unemployment 2011. Retrieved March 30, 2014 from http://laborcenter.berkeley.edu/blackworkers/Black_Employment and Unemployment 2011.pdf

Vogel, S., \& Reder, S. (1998). Educational attainment of adults with learning disabilities. In S. Vogel \& S. Reder (Eds.). Learning disabilities, literacy, and adult education. (pp. 43 - 68). London: Brookes

Eun Ji, PhD, is Assistant Professor, Counseling Psychology, Anyang University, Republic of Korea.

James Schaller, PhD, is Associate Professor, Rehabilitation Counselor Education, The University of Texas at Austin.

Barbara Pazey, PhD, is Assistant Professor, Department of Special Education, The University of Texas at Austin.

Kate Glynn, PhD, is Assistant Professor, Department of Rehabilitation and Disability Studies, Springfield College, Springfield, $M A$. 